\title{
Inadmisión y necesidad de reelaboración ante el derecho de acceso a la información pública
}

\section{The decision taken by public bodies of not processing a request of access to public information based in the compulsory requirement of a re-elaborating action}

\author{
Manuel Fernández Salmerón \\ Universidad de Murcia (España) \\ salmer@um.es
}

\begin{abstract}
NOTA BIOGRÁFICA
Manuel Fernández Salmerón es Licenciado en Ciencias de la Información por la Universidad Complutense y Doctor en Derecho por la Universidad de Bolonia. Es Profesor Titular de Derecho Administrativo de la Universidad de Murcia y está acreditado a CU. Sus principales líneas de investigación son: sistema de fuentes y control judicial de la actividad administrativa; procedimiento administrativo; Derecho Audiovisual; Derecho Ambiental; modernización y tecnificación del sector público; transparencia y privacidad en la actividad administrativa.
\end{abstract}

Javier Sierra Rodríguez

Universidad de Murcia (España)

ORCID: https://orcid.org/0000-0001-9002-5153

javier.sierra@um.es

\section{NOTA BIOGRÁFICA}

Javier Sierra Rodríguez es Licenciado en Ciencias Políticas y Doctor en Derecho por la Universidad de Murcia. Está acreditado como PCD y es profesor asociado del área de Ciencia Política en la Facultad de Derecho de la Universidad de Murcia. Sus líneas de investigación están relacionadas con la transparencia, el gobierno abierto y los sistemas electorales.

\section{RESUMEN}

El objetivo fundamental de este trabajo consiste en analizar las cuestiones más controvertidas que se han suscitado ante los tribunales, respecto de las causas de inadmisión de solicitudes acogidas al derecho de acceso y, específicamente, de la relativa a la necesidad de una acción de reelaboración. Los presupuestos legitimadores para la eficaz invocación de esta causa fueron examinados en la primera sentencia del Tribunal Supremo, dictada a raíz de una resolución del Consejo de la Transparencia y Buen Gobierno.

De su análisis se deriva que la interpretación judicial asume el cambio de modelo operado por la LTBG y la consideración del derecho de acceso a la información como una garantía expansiva, lo que conduce a una necesaria interpretación restrictiva de las causas de inadmisión. En lo referente al motivo basado en la necesidad de una acción de reelaboración, los criterios aceptados desembocan en la inadmisión cuando 
REALA. Nueva Época - N. ${ }^{\circ}$ 11, Abril-Septiembre 2019 - ISSN: 1989-8975 - DOI: 10.24965/reala.v0i11.10581 - [Págs. 56-74]

Inadmisión y necesidad de reelaboración ante el derecho de acceso a la información pública

Manuel Fernández Salmerón / Javier Sierra Rodríguez

las solicitudes fuerzan la elaboración ad hoc de un informe, sin perjuicio de asumir que todo otorgamiento del acceso requiere un mínimo de tratamiento, considerado tolerable. En cualquier caso, todavía es seguramente pronto para posicionamientos firmes y tajantes, requiriéndose una mayor producción jurisprudencial para delimitar con claridad los contornos de las causas de inadmisión, las cuales no dejan de estar formuladas como conceptos jurídicos indeterminados.

\title{
PALABRAS CLAVE
}

Derecho de acceso; inadmisión; procedimiento administrativo; reelaboración.

\begin{abstract}
The main aim of this work is to analyse the most controversial questions which have been raised in courts, regarding the causes of non-admission of applications based on the right of access to public information and, specially, the one linked to the necessity of a later re-elaborating action. The legitimacy for the effective invocation of this cause was revised in a groundbraking decision of the spanish Supreme Court, given after a resolution of the Council for Transparency and Good Governance.

From its analysis follows that judicial interpretation assumes the change of model operated by the transparency act, and the ensuing consideration of the right of access to public information as an example of "expansive right», which leads to an unavoidable restrictive interpretation of the causes of non-admission. Regarding to the specific cause based on the need of a re-elaboration action, the accepted criteria settle a due non-admission decision when the applications would force the elaboration of an «ad hoc» report to be granted, notwithstanding the assumption that any grant of the exercise of the right of access requires a minimum processing work, considered as tolerable. It is maybe still soon for positive and categorical assessments about this issue; being necessary more case-law production in order to delimit more clearly the outlines of all the non-admission causes, which are indeed formulated as legal indeterminate concepts.
\end{abstract}

\section{KEYWORDS}

Access to public information; non-admission; administrative procedure; re-elaborating action.

\section{SUMARIO}

1. INTRODUCCIÓN. 2. SOBRE LAS CAUSAS DE INADMISIÓN DEL DERECHO DE ACCESO. 2.1. LA INTERPRETACIÓN DE LOS CRITERIOS DE INADMISIÓN ANTE EL CARÁCTER EXPANSIVO DEL DERECHO DE ACCESO. 2.2. MOTIVACIÓN, SILENCIO ADMINISTRATIVO E INADMISIÓN DE SOLICITUDES DE ACCESO. SU ARTICULACIÓN EN SEDE JUDICIAL Y ANTE LOS ÓRGANOS ESPECIALES DE RECLAMACIÓN. 3. LA INADMISIÓN POR SER NECESARIA UNA ACCIÓN DE REELABORACIÓN. 3.1. LA ACCIÓN DE REELABORACIÓN SEGÚN EL CONSEJO DE TRANSPARENCIA Y BUEN GOBIERNO. 3.2. LA OMISIÓN DE LAACCIÓN DE REELABORACIÓN ANTE INFORMACIÓN EXISTENTE QUE SOLO REQUIERE SER RECOPILADA. a. Caso canales de televisión: producción de información inexistente. b. Caso Eurovisión 2015: simplicidad del tratamiento necesario. c. Caso: Gala Fin de Año 2015: producción de información inexistente. d. Caso: Especial Nochebuena y Campanadas 2016: recopilación de información existente. 4. A MODO DE CONCLUSIÓN. 5. REFERENCIAS BIBLIOGRÁFICAS.

\section{INTRODUCCIÓN}

El ejercicio del derecho de acceso a la información pública previsto en la Ley 19/2013, de 9 de diciembre, de Transparencia, Acceso a la Información Pública y Buen gobierno (LTBG) está limitado en función de la posibilidad de producir un perjuicio en torno a una serie de materias y derechos de terceros y, además, las solicitudes de acceso pueden ser inadmitidas por estar incursas en una serie de supuestos, al margen de las que hayan podido derivar de otras razones de tipo procedimental.

Las denegaciones son susceptibles de reclamación ante el Consejo de la Transparencia y Buen Gobierno (CTBG), mediante un recurso previsto en el artículo 24 de la LTBG, cuya resolución puede confirmarlas u otorgar el acceso, aunque se observa la tendencia del CTBG a resolver las reclamaciones manteniendo cierto criterio proclive a la transparencia y, consecuentemente, dado en mayor medida a permitir el acceso a la información pública. 
Durante estos años de funcionamiento y según la información que ofrece el CTBG, se han recibido 3.812 reclamaciones a fecha de 31 de diciembre de 2018, de las que 2.386 corresponden a la Administración General del Estado (AGE) ${ }^{1}$. En paralelo, el CTBG ha ido evacuando una serie de informes, que especifican los criterios para interpretar aquellos extremos de la LTBG que responden a conceptos jurídicos indeterminados o que precisan del análisis concreto de cada caso, de modo que se aclare el detalle para la correcta aplicación de los contenidos de la ley.

Era esperable que las resoluciones del CTBG fuesen recurridas en algunos casos ante los tribunales, bien por impulso de los solicitantes que no viesen satisfechas sus pretensiones o-como es habitual-, por parte de los sujetos obligados al suministro de la información por desacuerdo con ellas. Los primeros recursos en sede judicial se interpusieron contra resoluciones del CTBG de 2015, y en años posteriores se han visto incrementados, dando tiempo suficiente como para contar con un primer grupo de sentencias sobre la materia que tratan sobre los límites y los criterios de inadmisión. Adicionalmente DE LA NUEZ SÁNCHEZCASADO (2017: 6) recuerda que estos recursos realmente pueden estar motivados por el ánimo de «dificultar o dilatar el acceso a una información que se considera sensible desde un punto de vista político», aunque estos elementos -límites y causas de inadmisión- puedan ser formalmente alegados en los recursos como argumentos para apoyar la no concesión del acceso.

EI CTBG contabiliza actualmente más de ciento diez resoluciones en el ámbito de la AGE que han sido recurridas ante la jurisdicción contencioso-administrativa, de las cuales cerca de setenta ya han tenido algún pronunciamiento de los tribunales ${ }^{2}$. Además, ha sido en 2017 cuando se ha dictado la primera Sentencia que ha llegado al Tribunal Supremo a través de un recurso de casación, a partir de una resolución recurrida del CTBG. Dicha sentencia trae causa en una solicitud de acceso a información sobre los gastos en que la Corporación de Radio Televisión Española (CRTVE) incurrió por participar en el festival de Eurovisión de 2015, que, tras ser denegada por silencio administrativo, fue estimada por el CTBG, cuyo parecer fue confirmado posteriormente hasta en tres ocasiones.

Resulta destacable que varias de las resoluciones del CTBG que han terminado en los tribunales están relacionadas con el acceso a información de la CRTVE. En varios de esos casos, los fundamentos jurídicos de los recursos abordan la necesidad de reelaboración de la información como causa de inadmisión que motiva la no concesión de acceso. Hay que resaltar en relación con este aspecto, que las sentencias de diversas instancias han ido en direcciones opuestas según los casos, por lo que aumenta el interés de su análisis para delimitar claramente los criterios que permiten valorar cuándo es o no válida la inadmisión por esta causa.

El objeto principal de este trabajo consiste en el examen de las cuestiones más controvertidas que se han suscitado ante los tribunales respecto de las causas de inadmisión de solicitudes de acceso a la información pública, y específicamente, en relación a la causa consistente en la necesidad de una acción de reelaboración, complementando así otros trabajos que se han centrado especialmente en las resoluciones de los organismos de garantía (BARRERO, 2017).

Así, en primer lugar se estudia, por un lado, el tipo de interpretación aplicada en sede judicial (restrictiva o extensiva), dada la formulación de las causas como conceptos jurídicos indeterminados, mientras que, por otro lado, se analiza la actuación judicial respecto a la invocación de estas causas en el seno de procedimientos derivados de un previo silencio administrativo. En segundo lugar, se examina la causa relativa a la necesidad de una acción de reelaboración, por ser uno de los motivos habituales esgrimidos para no otorgar el acceso, y porque ha sido tratado extensamente por los tribunales.

Para ello, se recurre al análisis de la regulación estatal y autonómica ${ }^{3}$, a la doctrina jurídica y del CTBG, así como a la jurisprudencia reciente sobre la materia. El análisis de las sentencias dictadas ante reclamaciones constituye un ámbito de especial interés, por cuanto su conocimiento contribuye a configurar adecuadamente el alcance del derecho de acceso, su ejercicio, y para determinar claramente cuáles son las reglas y criterios a aplicar que permiten apreciar un supuesto de inadmisión de solicitudes de acceso más allá de lo que establece la ley.

\footnotetext{
1 La cantidad restante corresponde a las reclamaciones recibidas en relación a las Administraciones territoriales, entre las que se encuentran las de aquellas Comunidades Autónomas cuyas resoluciones son asumidas por el CTBG, en función de la suscripción del convenio regulado en el artículo 24.6 LTBG.

2 Informe de estadísticas del CTBG a fecha de 31 de diciembre de 2018 y documento del censo de recursos contra resoluciones del CTBG.

3 En la actualidad existen quince leyes autonómicas de transparencia y algunas tratan, además, temas afines como el gobierno abierto o la participación. De ellas, dos mantienen contenidos vigentes que son anteriores a la LTBG (Extremadura e Islas Baleares). Las dos Comunidades Autónomas restantes están en diversas fases de tramitación (Comunidad de Madrid y País Vasco).
} 
REALA. Nueva Época - N. ${ }^{11}$, Abril-Septiembre 2019 - ISSN: 1989-8975 - DOI: 10.24965/reala.v0i11.10581 - [Págs. 56-74]

Inadmisión y necesidad de reelaboración ante el derecho de acceso a la información pública

Manuel Fernández Salmerón / Javier Sierra Rodríguez

Debido a lo reciente de las últimas Sentencias -que no siempre han seguido criterios convergentes-, resulta de especial relevancia el estudio de las argumentaciones que los tribunales adoptan y su contraste con el contenido de la normativa, la postura que ha adoptado la doctrina y el CTBG en sus resoluciones y en los criterios interpretativos de la ley evacuados a tenor de sus competencias.

\section{SOBRE LAS CAUSAS DE INADMISIÓN DEL DERECHO DE ACCESO}

Las principales causas para la no concesión del acceso que han terminado en litigio están relacionadas con los límites establecidos expresamente en los artículos 14 y 15 de la LTBG, así como por los supuestos de inadmisión del artículo 18. Todas ellas están así diferenciadas, pero podrían considerarse conjuntamente como excepciones a la obligación de suministrar información, tal y como proponía FERNÁNDEZ RAMOS (2013: 253), a imitación de lo establecido por la Ley 27/2006, de 18 de julio, por la que se regulan los derechos de acceso a la información, de participación pública y de acceso a la justicia en materia de medio ambiente (LAPJMA). A continuación, se realizan unas consideraciones generales sobre las causas de inadmisión.

Es importante diferenciar adecuadamente entre la admisión y los límites del derecho de acceso ${ }^{4}$. Como bien puntualiza MORETÓN TOQUERO (2014: 16), el «efecto de la inadmisión resulta en la práctica limitador del derecho de acceso por cuanto lo excluye», es decir, limita el derecho, pero no porque las causas de inadmisión tengan esa naturaleza, sino porque sus efectos la producen, de ahí que haya que tener presente que cada una de las causas de inadmisión es «un criterio delimitador del objeto del derecho de acceso», pero no un límite en sí mismo.

Conviene, asimismo, señalar que la inadmisión ha consistido, tradicionalmente, en un pronunciamiento del órgano administrativo (o jurisdiccional), que tiene el efecto de rechazar formalmente las pretensiones del solicitante, pero debido a la concurrencia de razones que, precisamente, le impiden un pronunciamiento sobre el fondo de lo solicitado. A pesar de ello, modernamente hemos asistido a una neta dilatación de las funciones de la inadmisión, bien como herramienta de economía procesal o de descongestión o preservación de ciertos cauces procesales (CIERCO SEIRA, 2009: 38-50). Asimismo, algunas causas de inadmisión han visto adulterada su teleología, al vincularse irremediablemente con la cuestión de fondo, lo que también ha sucedido, en alguna medida con el ejercicio del derecho de acceso.

Hecha esta aclaración, el artículo 18 LTBG establece los criterios de inadmisión de solicitudes, delimitando como causas que la información solicitada esté en curso de elaboración o publicación general, tenga carácter auxiliar o de apoyo (notas, borradores, opiniones, resúmenes, comunicación o informes internos), sea necesaria su reelaboración, se dirijan a un órgano que no posea la información y se desconozca el competente, o que sean manifiestamente repetitivas o tengan un carácter abusivo ${ }^{5}$.

Estos contenidos de la Ley difieren de la tendencia europea, que es aparentemente más restrictiva respecto de los supuestos que se pueden asimilar a la inadmisión. Así, el artículo 5 del Convenio núm. 205 del Consejo de Europa sobre Acceso a Documentos Públicos de 2009 (Convenio de Troms $\varnothing$ ), únicamente contempla dos hipótesis como causas de rechazo en la tramitación de solicitudes. Por un lado, cuando la solicitud no sea razonable y, por otro, cuando se formule de manera tan vaga que la información no pueda ser identificada. Estos dos supuestos contrastan con los cinco casos que la Ley contempla como posibles causas de inadmisión.

Por otro lado, el Reglamento 1049/2001, de 30 de mayo, del Parlamento y del Consejo, relativo al acceso del público a los documentos del Parlamento Europeo, del Consejo y de la Comisión, establece límites

\footnotetext{
4 Por límites hacemos referencia a los que derivan del respeto a la protección de datos personales (art. 15 LTBG), así como los que se establecen ante la existencia de un perjuicio ante una serie de materia del artículo 14.1 LTBG: «a) La seguridad nacional. b) La defensa. c) Las relaciones exteriores. d) La seguridad pública. e) La prevención, investigación y sanción de los ilícitos penales, administrativos o disciplinarios. f) La igualdad de las partes en los procesos judiciales y la tutela judicial efectiva. $g$ ) Las funciones administrativas de vigilancia, inspección y control. h) Los intereses económicos y comerciales. i) La política económica y monetaria. j) El secreto profesional y la propiedad intelectual e industrial. k) La garantía de la confidencialidad o el secreto requerido en procesos de toma de decisión. l) La protección del medio ambiente».

5 Así, el artículo 18 LTBG se expresa del siguiente modo: «Causas de inadmisión. 1. Se inadmitirán a trámite, mediante resolución motivada, las solicitudes: a) Que se refieran a información que esté en curso de elaboración o de publicación general. b) Referidas a información que tenga carácter auxiliar o de apoyo como la contenida en notas, borradores, opiniones, resúmenes, comunicaciones e informes internos o entre órganos o entidades administrativas. c) Relativas a información para cuya divulgación sea necesaria una acción previa de reelaboración. d) Dirigidas a un órgano en cuyo poder no obre la información cuando se desconozca el competente. e) Que sean manifiestamente repetitivas o tengan un carácter abusivo no justificado con la finalidad de transparencia de esta Ley. 2. En el caso en que se inadmita la solicitud por concurrir la causa prevista en la letra d) del apartado anterior, el órgano que acuerde la inadmisión deberá indicar en la resolución el órgano que, a su juicio, es competente para conocer de la solicitud».
} 
propiamente dichos como los contemplados en los artículos 14 y 15 LTBG. Además, en el marco de los documentos relacionados con cualquier perjuicio a los procesos de toma de decisiones (artículo $14.1 \mathrm{k}$ ), añade una limitación que podría ser equivalente al supuesto de inadmisión que se establece en el apartado b) del artículo 18.1, al denegar el acceso a todo aquel documento que "contenga opiniones para uso interno, en el marco de deliberaciones o consultas previas en el seno de la institución, incluso después de adoptada la decisión», aunque a continuación, vuelve a restringir dicha limitación a que «la divulgación del documento perjudicara gravemente el proceso de toma de decisiones».

\subsection{La interpretación de los criterios de inadmisión ante el carácter expansivo del derecho de acceso}

Diversos autores, como RAMS RAMOS (2016: 21), alertan sobre la inadmisión como fenómeno que puede tener como efecto «verdaderas limitaciones sustantivas» que se ven desprovistas de ponderación, test de daño o de necesidad de audiencia, como sucede con el resto de los límites impuestos al ejercicio de este derecho. Hay que tener en cuenta que los criterios de inadmisión manejan una serie de conceptos jurídicos indeterminados, que dejan abiertas distintas vías para su interpretación y «que de ser utilizados abusivamente por los sujetos obligados podrían vaciar de contenido el derecho de acceso».

Tal y como están formulados los supuestos de inadmisión, con un amplio margen para la apreciación subjetiva, los sujetos obligados pueden pretender que tengan un alcance amplio, lo que choca frontalmente con las aspiraciones de la norma expresada en su Preámbulo, cuya literalidad ha sido recordada en numerosas ocasiones por las sentencias dictadas en procesos promovidos contra resoluciones del CTBG.

De ahí que, a la hora de interpretar los límites y las causas de inadmisión, el Tribunal Supremo en su sentencia sobre el "caso Eurovisión» (STS 1547/2017, de 16 de octubre), haya recordado que cualquier pronunciamiento sobre las circunstancias habilitantes de la inadmisión «debe tomar como premisa la formulación amplia y expansiva con la que aparece configurado el derecho de acceso a la información en la Ley 19/2013» (FJ 4. ${ }^{\circ}$ ). Recuerda el Alto Tribunal que el derecho de acceso a la información se reconoce:

«como un auténtico derecho a acceder a la información pública en los términos previstos en el artículo 105.b) de la Constitución Española» y que «la Ley configura de forma amplia ese derecho a la información pública, del que son titulares todas las personas y que podrá ejercerse sin necesidad de motivar la solicitud; que este derecho solamente se verá limitado en aquellos casos en que así sea necesario por la propia naturaleza de la información -derivado de lo dispuesto en la Constitución Española- o por su entrada en conflicto con otros intereses protegidos; y, en fin, que, en todo caso, los límites previstos se aplicarán atendiendo a un test de daño (del interés que se salvaguarda con el límite) y de interés público en la divulgación (que en el caso concreto no prevalezca el interés público en la divulgación de la información) y de forma proporcionada y limitada por su objeto y finalidad» (FJ $\left.4 .^{\circ}\right)$.

Por lo que concluye que «la formulación amplia en el reconocimiento y en la regulación legal del derecho de acceso a la información obliga a interpretar de forma estricta, cuando no restrictiva, tanto las limitaciones a ese derecho que se contemplan en el artículo 14.1. de la Ley 19/2013, como las causas de inadmisión de solicitudes de información que aparecen enumeradas en el artículo 18.1, sin que quepa aceptar limitaciones que supongan un menoscabo injustificado y desproporcionado del derecho de acceso a la información». De modo que bajo esta postura «restrictiva» de los límites al derecho y de las causas de inadmisión de solicitudes, ante la configuración expansiva del derecho de acceso, sólo serían aceptables las causas de inadmisión que estén justificadas «de manera clara y suficiente» (FJ 6. ${ }^{\circ}$ ).

En relación al carácter expansivo del derecho de acceso y su correlativo efecto constrictor de cualquier limitación que se quiera establecer, también se suele hacer alusión en las sentencias a la interpretación que ha realizado el Tribunal Europeo de Derechos Humanos $(\text { TEDH })^{6}$ acerca del alcance del artículo 10 del Convenio Europeo de Derechos Humanos ${ }^{7}$.

En este preciso sentido y tomando como sustento, en muy buena medida, la jurisprudencia de Estrasburgo, conviene reparar en la creciente tendencia doctrinal a otorgar al acceso a la información pública el

\footnotetext{
${ }^{6}$ Véase principalmente la STEHD, de 8-11-2016 (caso Magyar) y el análisis que realiza Lorenzo COTINO (2017: 287 y ss.) sobre el test que confecciona el TEDH para determinar los casos en los que en el derecho de acceso debe tener una mayor protección en atención a su carácter como derecho fundamental.

${ }^{7}$ SAN, de 25 de julio de 2017, Sala de lo Contencioso Administrativo, Sec. 7. ${ }^{a}$, Rec. 46/2017, FJ 2. ${ }^{\circ}$
} 
rango de auténtico derecho fundamental, desde la perspectiva del ordenamiento jurídico-constitucional interno. Aunque el Tribunal Constitucional no ha admitido aún con plenitud esta caracterización, ciertos autores han encontrado en el derecho a recibir información, previsto en el art. $20 \mathrm{CE}$, la matriz a partir de la cual emergería, como una de sus manifestaciones, la naturaleza fundamental del derecho de acceso, siguiendo, precisamente, la estela del TEDH (FERNÁNDEZ RAMOS, 2017b; COTINO HUESO, 2014; SÁNCHEZ DE DIEGO FERNÁNDEZ DE LA RIVA, 2016; RAMS RAMOS, 2013) ${ }^{8}$.

Se dirá que ello no tendría por qué influir de modo radical en la configuración del régimen de admisión de las solicitudes de acceso, sobre todo a la vista de la trayectoria, no siempre aleccionadora, seguida en el diseño del régimen de inadmisión de los recursos de amparo (CIERCO SEIRA, 2009: 51 y ss.). Es cierto, pero conviene adoptar la perspectiva adecuada en este tema. Primero, que el recurso de amparo esté o haya estado sometido en su admisión a trámite a un régimen restrictivo, nada tiene que ver con que dicha restricción sea extrapolable al ejercicio mismo del derecho fundamental cuya tutela constitucional se impetra. Segundo y consiguiente, resultaría incoherente, pues, tratar de establecer un paralelismo entre ambos regímenes de admisión. Esto es, entre, de un lado, el propio de la más alta magistratura que nuestro sistema contempla para la defensa de la CE, sometido a una presión resolutoria enorme, pero que se inserta en un sistema en el que existen abundantes posibilidades de obtener la tutela del derecho, protegido también en los escalones intermedios del sistema judicial. Y, de otro lado, el régimen de admisión que se aplicaría por parte de organizaciones administrativas puramente vicarias, permanentemente necesitadas de justificación en sus acciones y sometidas, estrictamente, al ordenamiento jurídico general, sobre todo en un campo de actividad afectante a la órbita de derechos de los ciudadanos, como es este.

En realidad y al margen del debate sobre la reconducción del derecho de acceso general al ámbito de los derechos fundamentales, conviene reparar en el incuestionable cambio de modelo operado en la configuración de este derecho, a partir de la LTBG. En efecto, hemos transitado en España desde una articulación clásica -netamente individual y defensiva del derecho de acceso-, hacia una arquitectura desvinculada de una legitimación personalizada en el requirente de acceso, más abierta, centrada en una apertura y transparencia general del aparato público y en su exposición «por defecto» al escrutinio cívico y democrático, en el que su objeto mismo es la información pública, al margen de su incorporación o no a un procedimiento.

Estos y otros rasgos sirven para caracterizar dos modelos de acceso a la información pública en buena medida ideales (CARLONI, 2014: 136-140). El que está basado esencialmente en la experiencia norteamericana de la FOIA (Freedom of Information Act), frente a ese otro modelo clásico -que ha regido en España a partir de la redacción originaria del art. 37 de la Ley 30/1992, de 26 de noviembre (LRJ-PAC)-, fundamentado en una opacidad general o "por defecto», con aperturas selectivas, activadas siempre a instancia de ciudadanos individuales, a los que se exigiría la titularidad de una posición jurídica subjetiva cualificada, que, en consecuencia, han de fundamentar su solicitud de acceso en la defensa de un derecho o interés legítimo, y que opera exclusivamente sobre información pública vinculada a la actividad administrativa formalizada (procedimientos o expedientes).

Por si fuera poco, no debe olvidarse que -como en parte se vuelve a insistir seguidamente- la consideración de la inadmisión como una operación frustrante de una respuesta de fondo, con tintes de «anomalía», postula una constante interpretación restrictiva de sus causas determinantes, así como un examen ponderado y sereno sobre su concurrencia, al margen de cualquier consideración sobre la posición subjetiva de fondo afectada por el procedimiento. Esta postura ha sido mantenida por autores como CIERCO SEIRA (2009:151 y ss.) en relación con la inadmisión en los procedimientos de revisión de oficio, aunque sus conclusiones son extrapolables a cualesquiera otras potestades o funciones.

A la vista de todo lo expuesto, parece poco cuestionable que cualquier interpretación de los supuestos de inadmisión deba realizarse bajo una perspectiva restrictiva ${ }^{9}$, algo que a priori no parece haberse reflejado

\footnotetext{
${ }^{8}$ Conviene, no obstante, referir que existen vehementes posiciones opuestas, como las de los profesores Tomás Ramón FERNÁNDEZ o Benigno PENDÁS, como puede comprobarse por sus comparecencias parlamentarias durante la tramitación del proyecto de la que luego sería la LTBG (GUICHOT REINA, 2014: 37).

${ }_{9}$ La reconducción del acceso a la categoría de los derechos fundamentales, que hoy parece dominante en nuestro panorama doctrinal, es un tema sobre el que no podemos detenernos, con la profundidad necesaria en este trabajo. Ahora bien, su afirmación debe conllevar obligatoriamente un considerable impacto sobre la interpretación de las causas de inadmisión de las solicitudes de acceso y su escrutinio judicial. No se trata, por lo demás, de un fenómeno novedoso, pues parecidas consideraciones se han venido haciendo en nuestro ordenamiento jurídico en relación con el derecho de acceso de los concejales a la información municipal, unánimemente considerado como una facultad inherente al derecho de los ciudadanos «a participar en los asuntos públicos, [...] por medio de representantes, libremente elegidos en elecciones periódicas por sufragio universal», reconocido en el art. 23.1 CE. Como se ha
} 
-con la intensidad necesaria-, en los criterios interpretativos del CTBG que ha dictado respecto a tres de los supuestos de inadmisión. En concreto, se han formulado tales criterios respecto de aquella información que tenga carácter auxiliar o de apoyo, que requiera reelaboración, o que se trate de solicitudes de información repetitivas o abusivas. En el resto de casos y en ausencia de unos criterios específicos, como es el caso de la información en curso de elaboración y publicación general, o que se dirija a un órgano en cuyo poder no obre la información cuando se desconozca el competente, hay que recurrir a la doctrina y a las resoluciones del CTBG para dilucidar adecuadamente el alcance de la inadmisión ${ }^{10}$.

La existencia de estos criterios interpretativos es transcendente. En primer lugar, porque la propia ley otorga la facultad de "adoptar criterios de interpretación uniforme de las obligaciones contenidas en la ley» (art. 38.2.a) a la Presidencia del CTBG, es decir, de erigirse en el órgano de referencia de interpretación de la Ley, al margen de la inexpropiable capacidad de jueces y tribunales para hacerlo. En segundo lugar, la jurisprudencia analizada está tomando como referencia dichos criterios interpretativos para apoyar la argumentación jurídica de algunas de sus sentencias ${ }^{11}$, aludiendo expresamente al valor reforzado que poseen los criterios interpretativos por el hecho de que la Comisión de Transparencia del CTBG debe emitir informe previo a su adopción ${ }^{12}$, y porque la misma está formada por integrantes de procedencias cualificadas, entre las que se encuentra la Autoridad Independiente de Responsabilidad Fiscal, el Tribunal de Cuentas, el Congreso, el Senado, la Agencia Española de Protección de Datos, el Defensor del Pueblo y el Ministerio de Hacienda.

Cabe mencionar en este apartado, que en el Derecho autonómico se encuentran algunas precisiones adicionales, que complementan los supuestos de inadmisión comunes que se expresan en la LTBG ${ }^{13}$. Así, sucede en las Leyes de transparencia de Andalucía ${ }^{14}$, Aragón ${ }^{15}$, Canarias ${ }^{16}$, Cataluña ${ }^{17}$, Cantabria ${ }^{18}$, Castilla La Mancha ${ }^{19}$, Comunidad Valenciana ${ }^{20}$, Navarra ${ }^{21}$ y Región de Murcia ${ }^{22}$, que han establecido de forma expresa una serie de reglas para fijar criterios específicos respecto a las causas de inadmisión de la LTBG. Entre estas reglas, se localizan, por ejemplo, la obligación de indicar el tiempo estimado para la conclusión de la información, cuando se inadmita una solicitud ante información en curso de elaboración; la exclusión de los informes de naturaleza preceptiva como causa de inadmisión por su carácter auxiliar o de apoyo; o la

explicado por gran número de autores (e.g. ORTEGAÁLVAREZ, 2003; FERNÁNDEZ RAMOS, 2003), esta especial naturaleza del derecho de acceso en la esfera local le ha otorgado, tradicionalmente, rasgos distintivos frente a aquel de que son titulares el común de los ciudadanos (con igual fundamento constitucional, pero esta vez radicado en el art. $105 b \mathrm{CE}$ ), destacando una interpretación restrictiva de sus límites, ya sean adjetivos, ya sustanciales.

10 BARRERO RODRÍGUEZ (2017:45) destaca el esfuerzo que han realizado, tanto el CTBG como sus homólogos de las Comunidades Autónomas, para perfilar los criterios de aplicación de las causas de inadmisión, aunque detecta que se sigue manteniendo «un importante margen de apreciación sobre la concurrencia o no, ante las circunstancias particulares de cada caso» y que, además, sería conveniente matizar o perfilar los criterios interpretativos del CTBG una vez transcurrido un periodo prudencial, porque en algún caso este órgano no «absorbe todos los supuestos posibles» en algunas causas de inadmisión.

11 Véase el Caso entrevistas personales, SJCCA núm. 10 de 28 de noviembre de 2016, núm. 159/2016, FJ 3. ${ }^{\circ}$ (confirmada por SAN, de 24 de abril de 2017, núm. Res. 162/2017, Sec. 7.a).

12 Vid. el artículo 8.2 b del Real Decreto 919/2014, de 31 de octubre, por el que se aprueba el Estatuto del Consejo de Transparencia y Buen Gobierno.

${ }_{13}$ Las leyes autonómicas de transparencia son bastante redundantes, sin que en términos generales se hayan apartado de lo establecido por la normativa estatal. Se echa de menos que, por cuestiones de aplicación de una técnica legislativa más acertada, no hubiese una reproducción de la norma estatal tan idéntica para plasmar los mismos contenidos en muchas de ellas, y que se hubiese optado por una remisión general, dejando solamente los contenidos propios que aportan las normas autonómicas.

${ }_{14}$ Ley $1 / 2014$, de 24 de junio, de Transparencia Pública de Andalucía.

15 Ley 8/2015, de 25 de marzo, de Transparencia de la Actividad Pública y Participación Ciudadana de Aragón.

16 La norma canaria, Ley 12/2014, de 26 de diciembre, de transparencia y de acceso a la información pública, incluye además una causa adicional de inadmisión en su artículo 43.1.f) relativa a las solicitudes «Que afecten a una pluralidad de personas cuyos datos personales pudieran revelarse con el acceso a la petición, en número tal que no sea posible darles traslado de la solicitud en el tiempo establecido para su resolución». Durante el proceso de elaboración de la norma, se contempló la posibilidad de incluir este supuesto en la LTBG, pero finalmente no prosperó. Su mera propuesta como causa de inadmisión fue criticada porque en todo caso, sus previsiones deberían llevar a una ampliación de los plazos, pero no a una inadmisión (FERNÁNDEZ RAMOS, 2013:269).

17 La Ley 19/2014, de 29 de diciembre, de transparencia, acceso a la información pública y buen gobierno de la Generalitat varía respecto a las causas de inadmisión y no refleja el equivalente a las causas que se originan ante desconocimiento del órgano que posea la información o ante solicitudes repetitivas o abusivas.

18 Ley 1/2018, de 21 de marzo de Transparencia de la Actividad Pública de Cantabria.

19 Ley 4/2016, de 15 de diciembre, de Transparencia y Buen Gobierno de Castilla-La Mancha.

20 Ley $2 / 2015$, de 2 de abril, de Transparencia, Buen Gobierno y Participación Ciudadana de la Comunitat Valenciana.

${ }^{21}$ Ley Foral 5/2018, de 17 de mayo, de Transparencia, Acceso a la Información Pública y Buen Gobierno. Murcia.

22 Ley $12 / 2014$, de 16 de diciembre, de Transparencia y Participación Ciudadana de la Comunidad Autónoma de la Región de 
imposibilidad de inadmitir bajo la causa de reelaboración aquella información que pueda obtenerse mediante un tratamiento informatizado de uso corriente, entre otras.

Aparte quedan normas como la extremeña ${ }^{23}$ que no realiza aclaraciones adicionales y las Leyes de Asturias ${ }^{24}$, Castilla y León ${ }^{25}$, Galicia ${ }^{26}$, Islas Baleares ${ }^{27}$ y La Rioja ${ }^{28}$, que directamente no regulan las causas de inadmisión y deben guiarse por la normativa estatal, bien porque son anteriores a la LTBG o porque hagan una remisión expresa a ella.

En este sentido, conviene recordar que, como ha venido a señalar doctrina autorizada, no resulta constitucionalmente tolerable el establecimiento, por parte de los legisladores autonómicos, de causas de inadmisión adicionales a las dispuestas por la legislación básica del Estado (FERNÁNDEZ RAMOS y PÉREZ MONGUIÓ, 2017:225; BARRERO RODRÍGUEZ, 2017:3). Es este un problema que se extiende, además, a otras determinaciones procedimentales esenciales en el ejercicio de este derecho y cuya fijación unívoca y cerrada corresponde al legislador estatal. Entre ellas, están las relativas al sentido del silencio administrativo -sobre la que ya ha recaído pronunciamiento por parte del TC, que ha declarado inconstitucional algunos preceptos la norma aragonesa ${ }^{29}$ - o el establecimiento de cualesquiera otras especialidades procedimentales. De ahí que pueda ser objeto de crítica que la normativa autonómica fije, ya no solo reglas, sino prácticamente supuestos de nueva redacción, como sucede en la Ley Foral 5/2018, de 17 de mayo, con una serie de añadidos como causa de inadmisión que se alejan de la redacción de la LTBG, aunque finalmente pueda existir mucha equivalencia y pudieran considerarse que quedan subsumidas en éstas ${ }^{30}$.

\subsection{Motivación, silencio administrativo e inadmisión de solicitudes de acceso. Su articulación en sede judicial y ante los órganos especiales de reclamación}

La inadmisión da como resultado la finalización del procedimiento, aunque se destaca la obligación, que establece el mismo artículo 18.1 LTBG, de motivar los casos en los que se aplica. Según los criterios interpretativos del CTBG, dicha motivación debe hacer expresas las causas de inadmisión y su justificación legal o material; asimismo, la justificación de la decisión debe hacerse de forma concreta y aplicada al caso de que se trate, por lo que se deduce que no sería válida como motivación la invocación de causas de carácter general.

Sin embargo, se puede producir cierta rotura del esquema que plantea la Ley cuando, ante solicitudes de acceso a la información, opere la institución del silencio administrativo. En tal caso, la inactividad administrativa tiene, como hemos dicho, efectos negativos, según lo prevenido en el artículo 20.4 LTBG, lo que abre a los solicitantes la posibilidad de interponer ante el CTBG el recurso previsto en el artículo 24. Del análisis de la jurisprudencia se observa cómo, en algunos casos, el silencio administrativo ha pretendido ser utilizado por los sujetos públicos obligados para esquivar la necesidad de motivación, lo que posteriormente y en sede judicial, han defendido como situaciones susceptibles de haber incurrido en causa de inadmisión o de infringir los límites que la ley establece.

Así sucedió en el caso «Gastos de Eurovisión 2015», en el que la CRTVE pretendía hacer valer que la solicitud incurría en una de las causas de inadmisión, por lo que -recuerda el tribunal- la decisión habría requerido una resolución motivada, algo que no se dio en este supuesto. Por lo tanto, no procedería a pos-

23 Dicha norma, Ley 4/2013, de 21 de mayo, de Gobierno Abierto de Extremadura, regula además una causa de inadmisión que solo tiene equivalente en la norma canaria y que se refiere a aquellas solicitudes que afecten a una pluralidad de personas «cuyos datos personales pudieran revelarse con el acceso a la petición, en número tal que no sea posible darles traslado de la solicitud en el tiempo establecido para su resolución» (art. 21.d).

24 Ley 8/2018, de 14 de septiembre, de Transparencia, Buen Gobierno y Grupos de Interés.

25 Ley 3/2015, de 4 de marzo, de Transparencia y Participación Ciudadana de Castilla y León.

26 Ley 1/2016, de 18 de enero, de Transparencia y Buen Gobierno.

27 Ley 4/2011, de 31 de marzo, de la Buena Administración y del Buen Gobierno de las Illes Balears.

28 La Ley 3/2014, de 11 de septiembre, de Transparencia y Buen Gobierno de La Rioja, hace una remisión en su artículo 13 a la legislación básica del Estado para el ejercicio del derecho de acceso. No obstante, surgen dudas sobre la diferenciación que esta norma hace entre el derecho de acceso y las solicitudes de documentos y datos del sector público autonómico con finalidades de reutilización, sobre los que en su artículo 26.4 establece como causa de inadmisión de solicitudes «que impliquen un trabajo desproporcionado para los servicios de la Administración autonómica o que carezcan manifiestamente de utilidad».

29 La STC 104/2018, de 4 de octubre, ha declarado inconstitucional, por invasión de la competencia exclusiva estatal respecto al procedimiento administrativo común, el sentido estimatorio del silencio dispuesto en el artículo 31.1 de la Ley de Transparencia de Aragón, por ser contradictorio con el efecto desestimatorio contemplado en la LTBG.

30 Entre ellas se pueden citar los apartados a y $c$ de su artículo 37: «a. Que se refieran a información que la ley excluya del derecho de acceso» y «c. Las peticiones de respuestas a consultas jurídicas o las peticiones de elaboración de informes o dictámenes». 
teriori asumir que concurrió una causa de inadmisión: «no habiéndose dictado una resolución expresa de inadmisión a trámite, no cabría tampoco entender infringido por la resolución impugnada», ya que el efecto del silencio no es la inadmisión de la solicitud, sino su desestimación ${ }^{31}$.

De hecho, hay que recordar que la resolución que emita el sujeto público obligado, por entender que se incurre en inadmisión, debe estar debidamente motivada especialmente ante causas de inadmisión construidas en torno a conceptos jurídicos indeterminados, cuya indefinición constitutiva exige, desde un punto de vista de pura justicia, un mayor énfasis sobre la interpretación seguida en el caso concreto por el sujeto público de que se trate (CIERCO SEIRA 2009: 243-244). Por ello, pretender la inadmisión en vía judicial tras no responder tempestivamente a la solicitud de acceso, y con ello, evitar la obligación de motivar una resolución, es una práctica escapista que debería conllevar un mayor reproche en vía judicial ${ }^{32}$, ya que, finalmente y pese a la advertencia que se hace constar en la sentencia, el tribunal entra a examinar la existencia o no de causas que lleven a la inadmisión. No obstante, bien es cierto que este aspecto parece ser esencial para desestimar las pretensiones de la CRTVE en apelación ${ }^{33}$ y casación, y que, como se recuerda en la sentencia de este último recurso, se tiene en cuenta que la CRTVE alegó la causa de inadmisión en el trámite de alegaciones previo a la resolución del CTBG, pese a que no había resuelto como procedía tras la solicitud de información ${ }^{34}$.

FERNÁNDEZ RAMOS (2017a: 61) recuerda que esta práctica no debe ser admitida «acríticamente» y reprocha la naturalidad con la que algunos organismos de garantía proceden a resolver las reclamaciones ante el silencio administrativo, sin advertir las previsiones del artículo 20.6 LTBG, en el que se establece que «el incumplimiento reiterado de la obligación de resolver en plazo tendrá la consideración de infracción grave a los efectos de la aplicación a sus responsables del régimen disciplinario previsto en la correspondiente normativa reguladora».

Asimismo, hay que tener en cuenta la existencia de sentencias que reconocen al CTBG la capacidad para detectar la presencia de causas de inadmisión, aun cuando no se haya resuelto en ese sentido por los sujetos públicos requeridos. Así, ante un caso de silencio administrativo en el que se alega tardíamente la causa de inadmisión en vía de reclamación, en el trámite de audiencia a las partes previo a la resolución del CTBG, el tribunal estima que este órgano administrativo de garantía «sí puede declarar la concurrencia de alguna de las causas de inadmisión de la petición de información recogidas en el artículo 18 de la Ley 19/2013», porque aun cuando «se desestima la petición de información por silencio administrativo, tiene plena competencia para analizar y valorar la totalidad de las causas de inadmisión o desestimación o estimación que puedan alegarse» ${ }^{35}$. Es decir, que se permite veladamente que se produzca el silencio administrativo y que el CTBG pueda reconocer que existe causa de inadmisión, aunque no haya resolución expresa de la organización a la que se haya solicitado la información.

No obstante, las prácticas problemáticas que se han expuesto tienen matices distintivos. Conviene no perder de vista que el planteamiento judicial consistente en no consentir el examen de una posible causa de inadmisión de la solicitud de acceso, que no fue advertida en el procedimiento inicial, es plenamente coherente con el posicionamiento, asimismo jurisdiccional, de retorno al carácter puramente revisor de la jurisdicción contencioso-administrativa en esta materia. En efecto, como ha destacado CIERCO SEIRA (2009: 278 y ss.), la tendencia judicial preponderante consiste, con carácter general, en no entrar en el enjuiciamiento de fondo cuando la Administración Pública ha pronunciado una resolución de inadmisión, limitando, pues, su fallo a la procedencia o no de ésta.

Si el juez no puede satisfacer la pretensión sustantiva que subyacía a la solicitud de acceso, porque el acto de la Administración Pública no le brindaba esa posibilidad, resulta hasta cierto punto coherente que aquél persista en negarse a hacer cualquier cosa -en el caso, evaluar la procedencia de la inadmisión- para lo que el acto nuevamente no le habilita. Pero, entiéndase bien. Este posicionamiento judicial mayoritario, nos parece hasta cierto punto razonable, en la medida en que no existe pronunciamiento administrativo

31 SJCCA núm. 6, de 18 de mayo de 2016, núm. 60/2016, FJ 3.․ .

32 Una de esas vías para la intensificación del reproche judicial a tales conductas fraudulentas, habría podido consistir en la imposición de las costas procesales a la Administración Pública que incurriera en ellas. Sobre esto, remitimos de nuevo a CIERCO SEIRA (2009: 297-298). No obstante, tal posibilidad quedó en buena medida cercenada tras la reforma del sistema de imposición de costas en el contencioso-administrativo, operada por la Ley 37/2011, de 10 de octubre, de medidas de agilización procesal, que proyectó también sobre este orden jurisdiccional la regla general victus victori.

33 SAN, de 7 de noviembre de 2016, núm. Res. 432/2016, Sec. 7 . $^{\text {a }}$

34 STS, de 16 de octubre de 2017, núm. 1547/2017, Sec. 3. ${ }^{a}$, FJ 3. ${ }^{\circ}$

35 SAN, de 27 de febrero de 2017, Sec. 7. ${ }^{a}$, núm. Res. 86/2017, FJ 6. ${ }^{\circ}$ 
previo sobre la inadmisión, lo que vetaría el posterior escrutinio judicial sobre ese particular. Ahora bien, si partimos de la necesidad de desembarazarse definitivamente de la servidumbre del acto administrativo y de su estricta revisión, dicha doctrina no puede, en cambio, ser tolerada. Y no puede serlo, toda vez que el enjuiciamiento de la actividad unilateral de las Administraciones Públicas -no puede olvidarse- tiene como objetivo prioritario la tutela judicial efectiva de los derechos e intereses de los ciudadanos, tal y como proclama taxativamente el art. $24 \mathrm{CE}$.

Sucede, pues, que el juez debe actuar de modo equivalente a la Administración, al resolver los recursos administrativos ${ }^{36}$. En efecto, en estos el órgano que debe resolver ha de decidir, ciertamente, dentro del ámbito de las pretensiones de los interesados, pero también -si bien, con previa audiencia- «cuantas cuestiones, tanto de forma como de fondo, plantee el procedimiento, hayan sido o no alegadas por los interesados» (art. 119.3 Ley 30/2015, de 1 de octubre). Pues bien, a una tarea similar ha de proceder el juez, con el énfasis añadido de que su deber de intentar un enjuiciamiento sobre el fondo del asunto es todavía mayor. En consecuencia, el juzgador ha de proceder a toda costa a un examen sobre el fondo de la solicitud de acceso, salvo que necesariamente concurra algún obstáculo insuperable.

No se trata de entrar ahora en el proceloso y controvertido debate sobre la posibilidad de introducción en el contencioso de motivos no alegados en vía administrativa, -frente a la prohibición de suscitar cuestiones nuevas-, pero sí conviene hacer algunas aclaraciones sobre el alcance de esta invocación extemporánea de las causas de inadmisión.

Primera. La Ley 9/1998, de 13 de julio, reguladora de la Jurisdicción Contencioso-administrativa (LJCA), admite que tanto el demandante, como el sujeto público demandado, puedan introducir nuevos motivos en la demanda o la contestación, «hayan sido o no planteados ante la Administración» (art. 56.1). A pesar de la equívoca redacción de este último inciso, parece que también la Administración Pública podría invocar la concurrencia de un motivo nuevo que amparase su pretensión (la declaración de ser conforme a Derecho el acto recurrido y, con ella, la denegación del derecho de acceso a los documentos por parte del solicitante), siempre que esta permanezca invariable ${ }^{37}$. En tal sentido, alegar en vía judicial la inadmisibilidad de la solicitud de acceso parece que debería ser admitido, con carácter general, si -insistimos- lo que se pretende es desvincular la labor jurisdiccional respecto de lo estrictamente valorado en sede administrativa.

Segunda. En los casos de desestimación ficticia por silencio ${ }^{38}$, es cierto que se produciría una relevante ausencia de motivación por parte de la Administración Pública respecto de la concurrencia de la causa de inadmisión ${ }^{39}$, pero una vez admitido que la Administración Pública demandada podría introducir en el proceso un nuevo motivo (en el caso, de inadmisión de la solicitud de acceso), tendría el correlativo deber de motivar su concurrencia ante el juez.

Tercera. Hay que tener en cuenta que la inadmisión tuvo en su origen la finalidad de economizar el despacho de los asuntos administrativos, permitiendo excluir la tramitación de aquellas solicitudes que, claramente, no podían comprenderse dentro de los parámetros (objetivos, subjetivos o funcionales) del correspondiente procedimiento.

Tres eran, pues, las notas distintivas esenciales de la inadmisión. De algún modo, operaba al margen de cualquier juicio sobre el fondo de lo suscitado y, en coherencia con ello, se basaba predominantemente en motivos de índole formal o en obstáculos procesales, dejando las apreciaciones sobre los límites sustantivos de

36 Los recursos resultan, a nuestro juicio, asimilables a las reclamaciones -reciban o no esta precisa denominación- habilitadas ante órganos especializados en materia de transparencia e implementados por las distintas Administraciones Públicas. Entre tales reclamaciones, destacan las previstas en el ámbito la estatal, residenciables ante el CTBG, argumento ex art. 112.2, Ley 39/2015, de 1 de octubre, del Procedimiento Administrativo Común de las Administraciones Públicas.

37 Cuestión, por supuesto, distinta es la de si, descartada la concurrencia de la causa de inadmisión, debe pasar el juez al enjuiciamiento de fondo de la solicitud de acceso, algo en lo que -nos reiteramos- creemos firmemente. Lo contrario ha constituido, en buena medida, la tónica jurisprudencial, severamente criticada por CIERCO SEIRA (2009: 287 y ss.). Salvo que se alce un obstáculo a dicho pronunciamiento de fondo, como el carácter discrecional de la apreciación de alguno de los límites sustantivos al acceso. Y lo cierto es que la mayor parte implican, con diverso alcance, el despliegue de un juicio discrecional (vid. el art. 14 LTBG). En tales casos, quedaría al juez el inexpropiable poder de enjuiciar el correcto ejercicio de la discrecionalidad, aunque no el de sustituir el núcleo de la valoración. El límite de la discrecionalidad parece, pues, a priori, claro. Vid. con carácter general, para supuestos parecidos al aquí analizado, un posicionamiento nítido desde antiguo en la mejor doctrina (CLAVERO ARÉVALO, 1963: 223-224).

38 Que serán la mayoría de los potencialmente posibles, pues solo en ellos la Administración Pública no habrá tenido, auténticamente, posibilidad de pronunciarse sobre la concurrencia de una causa de inadmisión.

39 Lo que no deja de ser relevante, pues algunas de las causas de inadmisión implican un amplio margen de apreciación, aunque no siempre pueda identificarse dicho margen con el ejercicio de discrecionalidad. El exponente sería, seguramente, el supuesto previsto en el art. 18.1 e LTBG: que las solicitudes «sean manifiestamente repetitivas o tengan un carácter abusivo no justificado con la finalidad de transparencia de esta Ley». 
los derechos o intereses invocados a la resolución final de los expedientes admitidos. Finalmente, tales causas de inadmisión se caracterizaban -en realidad, tenían sentido- por estar ubicadas en un momento inicial (liminar) del procedimiento. Cuando a las mismas se fueron incorporando otras con características distintas y más próximas a razones sustanciales y, por eso, a motivos de desestimación final de las pretensiones, esa necesaria evaluación liminar se fue relajando en un proceso de carácter evolutivo (CIERCO SEIRA, 2009: 82 y ss.).

Esto sucede también en materia de derecho de acceso, de modo que nos encontramos con motivos de inadmisión que, con independencia de los defectos que puedan presentar en su configuración, responden al modelo clásico expuesto. Tal sería el caso de los previstos en los apartados $d$ (solicitudes «dirigidas a un órgano en cuyo poder no obre la información cuando se desconozca el competente») y e («que sean manifiestamente repetitivas o tengan un carácter abusivo no justificado con la finalidad de transparencia de esta Ley») del art. 18.1 LTBG. Contrariamente, otros de los motivos legales de inadmisión responden a esa categoría más identificable con razones de fondo, como es el caso de los contemplados en los apartados $a$ y $b$ de dicho precepto ${ }^{40}$.

Pues bien, nos parece claro que únicamente podría admitirse la invocación procesal ex novo y, en definitiva, la aplicación extemporánea -en sede judicial o ante un órgano de reclamaciones- de una causa de inadmisión del derecho de acceso en estos últimos supuestos contemplados en el art. 18.1 a y $b$ LTBG -lo que implicaría, esencialmente, un pronunciamiento de desestimación-, pero de ningún modo en los primeros (apartados $d$ y e de dicho precepto), que necesariamente habrían de ser apreciados, expresamente y a limine, en el procedimiento administrativo previo.

Caso más dudoso sería, en cambio, el previsto en el apartado $c$ (sobre solicitudes «relativas a información para cuya divulgación sea necesaria una acción previa de reelaboración»), aunque seguramente fuera reconducible a los motivos que hemos señalado como equivalentes a exclusiones del acceso por razones de fondo (apartados $a$ y $b$ ) y, por lo tanto, podría tal vez invocarse extemporáneamente por la Administración Pública demandada.

Permitir que, tras meses o años de haber presentado la solicitud de acceso -sin haber recibido respuesta expresa de la Administración Pública o incluso habiéndola recibido-, ya en sede judicial, la Administración Pública demandada pueda alegar eficazmente la denegación del acceso por tratarse de una solicitud «manifiestamente repetitiva» ${ }^{41}$, que es un motivo de inadmisión claramente defensivo, generaría una situación de injusticia material clamorosa que, a nuestro juicio, no se debería permitir.

\section{LA INADMISIÓN POR SER NECESARIA UNA ACCIÓN DE REELABORACIÓN}

A continuación, se aborda la causa prevista en el art. 18 c LTBG, que establece el supuesto de aquellas solicitudes «relativas a información para cuya divulgación sea necesaria una acción previa de reelaboración». Esta causa de inadmisión es una de las que más ha sido esgrimida por los sujetos públicos obligados para rechazar la concesión de información, constituyendo una especie de comodín para aquellos que pretenden esquivar el otorgamiento del acceso. El problema de fondo sobre la «necesidad de reelaboración de información» reside en la adecuada interpretación de las circunstancias que permitan afirmar su concurrencia.

Frente a una redacción más limitada de la LTBG en este supuesto, cabe mencionar que la Ley andaluza ha adicionado un criterio para la aplicación de esta causa de inadmisión. En concreto, dicha Ley autonómica señala en su artículo $30 c$ que «no se estimará como reelaboración que justifique la inadmisión la información que pueda obtenerse mediante un tratamiento informatizado de uso corriente». Así, se vienen a admitir como válidas las solicitudes que requieran tratamiento, siempre que la complejidad del mismo esté circunscrita a un tratamiento informatizado que no requiera especial complejidad. Esta previsión guarda identidad con lo que se establece en las leyes de Comunidades Autónomas como Aragón (art. 30.1 a), Canarias (art. 43.2 c), Cantabria (12.1 c), Castilla La Mancha (art. 31.1 c), Comunidad Valenciana (art. 16.2 b), Navarra (art. $37 \mathrm{~g}$ ) y Región de Murcia (art. $26.4 \mathrm{c})^{42}$. Además, la Ley navarra concreta la exclusión de esta causa de inadmisión en la «acción que requiera aglutinar la información dispersa en varios documentos existentes» (art. $37 \mathrm{~g}$ ).

40 «a) Que se refieran a información que esté en curso de elaboración o de publicación general. b) Referidas a información que tenga carácter auxiliar o de apoyo como la contenida en notas, borradores, opiniones, resúmenes, comunicaciones e informes internos o entre órganos o entidades administrativas». En realidad, se trataría en última instancia de información y documentos no accesibles.

41 Sería también de por sí muy cuestionable que, en tales circunstancias, la Administración Pública ante la que se presentó la solicitud pudiera invocar, sin mayores consecuencias jurídicas, el desconocimiento a que se refiere el apartado $d$ del art. 18.1 LTBG.

42 La Ley de Extremadura solo establece el supuesto en los mismos términos que la LTBG. 
En el caso catalán (art. 29.1 b), la norma aborda este criterio de forma parcialmente equivalente, al condicionar que para esa elaboración o reelaboración sea «necesaria una tarea compleja». Además, en tal caso, la Ley añade como novedad la posibilidad de «dar la información de forma desglosada, previa audiencia del solicitante».

\subsection{La acción de reelaboración según el Consejo de Transparencia y Buen Gobierno}

El CTBG dictó, el 12 de noviembre, el Criterio 7/2015, sobre causas de inadmisión de solicitudes de información relativas a información para cuya divulgación sea necesaria una acción previa de reelaboración ${ }^{43}$. Para el desarrollo del criterio, el CTBG parte de la conceptualización de la información pública llevada a cabo en el artículo $13 \mathrm{LTBG}^{44}$, para diferenciarla a continuación de sus componentes, como son los datos y los documentos. Así, argumenta dicha instancia de garantía, que la información debe comprender necesariamente un mínimo de elaboración a partir de los datos y documentos existentes, por lo que no se incurre en el supuesto de inadmisión cuando se requiere la «mera agregación, o suma de datos, o el mínimo tratamiento de los mismos».

EI CTBG utiliza algunos de los supuestos previstos por la LTBG en otros artículos para diferenciarlos de la operación de «reelaboración» y, por tanto, excluirlos de la esfera en la que opera esta causa de inadmisión. Entre ellos, menciona la información voluminosa, que, al contrario de la que exige operaciones de reelaboración, no origina inadmisión y puede dar lugar a una ampliación del plazo para facilitar la información (art. 20.1 LTBG). También la distingue de las operaciones necesarias para que la información deba ser anonimizada o disociada respecto de los datos de carácter personal que contenga, en el sentido expresado por los artículos 15.4 y 16 de la Ley. No obstante, la parquedad explicativa del criterio interpretativo no permite tener clara la distinción, cuando dicho proceso de disociación conlleve una amplia carga de trabajo o requiera una amplia elaboración.

Por el contrario, el criterio interpretativo sí admite la existencia de reelaboración en los casos en que, para ofrecer la que se ha solicitado, sea necesario hacer uso de diversas fuentes de información, o cuando se haya solicitado información en un formato distinto de aquel en el que se conserva y la misma no sea reutilizable, exceptuando los casos específicos de extracción de información en formato Excel o Word, que no puede considerarse como una operación de reelaboración.

También, admite el CTBG que se proceda a la inadmisión de la solicitud cuando no se disponga «de los medios técnicos que sean necesarios para extraer y explotar la información concreta que se solicita, resultando imposible proporcionar la información solicitada». Este supuesto también se tolera como causa de inadmisión ante el requerimiento de información voluminosa en un contexto de falta de los medios necesarios.

Sobre el criterio interpretativo, BLANES CLIMENT (2015) critica, muy fundadamente, que se pueda inadmitir una solicitud de acceso si ello conlleva el volcado de datos de diversas fuentes ${ }^{45}$, ya que de este modo se estaría restringiendo el derecho a la información pública y degradándolo a un mero derecho al «documento ya existente», tal y como previamente argumenta el CTBG en su criterio para admitir cierto mínimo de reelaboración de la información, sin que sea objeto de inadmisión.

No parece faltar razón al autor. Al amparo de la LTBG, que recordamos, supone el tránsito hacia un modelo más abierto y transversal en cuanto al derecho de acceso a la información pública se refiere, no parece fundada la inadmisión de solicitudes de información que, no conllevando una tarea estricta de reelaboración, exijan del sujeto público obligado simplemente la agregación de lo requerido a partir de distintas fuentes. No se trata, a nuestro juicio, de la reducción del ahora examinado a un supuesto «derecho al documento existente», sino más bien de su degradación a un atípico «derecho a la información pública obrante en una sola fuente o sistema de información» ${ }^{46}$.

${ }^{43} \mathrm{Cl} / 7 / 2015$, de 12 de noviembre.

${ }_{44}$ Artículo 13. Información pública. "Se entiende por información pública los contenidos o documentos, cualquiera que sea su formato o soporte, que obren en poder de alguno de los sujetos incluidos en el ámbito de aplicación de este título y que hayan sido elaborados o adquiridos en el ejercicio de sus funciones».

${ }^{4}$ En la Ley navarra se excluye expresamente como supuesto de esta causa de inadmisión que la información esté dispersa en varios documentos existentes (art. $37 \mathrm{~g}$ ).

${ }^{46}$ En efecto, el concepto de documento no parece aquí del todo pertinente, pues, como ha señalado con justeza SENDíN GARCíA (2014), la necesaria interpretación amplia del mismo resulta suficiente para reconducirlo a un conjunto de unidades de información incorporado a un soporte, lo que remitiría derechamente nada menos que a la «universalidad», pues, al margen de la necesidad de reelaboración, no resulta sencillo concebir información no incorporada en algún soporte. Sobre esta acepción amplia, la Ley 16/1985, de 
Entiende el autor que el ciudadano no tiene por qué sufrir la falta de medios de las Administraciones y que las limitaciones de formato no están justificadas, tanto por no estar establecidas en la LTBG, como porque el acceso precisamente se concibe «preferentemente por vía electrónica». Además, permitir la causa de inadmisión por la inexistencia de los formatos solicitados, viene a ser un incentivo para la no imposición de formatos reutilizables y sin que tal imposición implicara, claro está, nada parecido a un «derecho al formato».

En cuanto a la posible fundamentación de una imposibilidad del acceso, debido a la carencia de medidas técnicas $u$ organizativas o de las adquisiciones materiales pertinentes por parte de la Administración Pública, hay que tener en cuenta que el reconocimiento de un derecho debe llevar «de suyo el correlativo deber para la Administración Pública de implementar los medios que garanticen su ejercicio, sin menoscabo naturalmente del funcionamiento del resto del aparato público», ya que «si, por el contrario, lo que pretendía conjurar este inciso era el abuso en el ejercicio de este derecho, seguramente nuestro ordenamiento ha dispuesto siempre de resortes suficientes para ello sin necesidad de menciones adicionales» (FERNÁNDEZ SALMERÓN, 2017:305, nota 49) ${ }^{47}$.

Finalmente, el Consejo en su criterio interpretativo aporta algunas pautas para determinar cuándo se entiende que la solicitud exige una labor de «reelaboración», para lo cual el sujeto público requerido deberá basarse en «elementos objetivables de carácter organizativo, funcional o presupuestario». Para BLANES CLIMENT (2015) estos elementos suponen una «tentación» para las Administraciones Públicas, debido a que se trata de conceptos jurídicos indeterminados, y puede recurrirse a ellos para inadmitir solicitudes «no cuando exista alguna imposibilidad, sino con una simple dificultad organizativa, funcional o presupuestaria» ${ }^{48}$.

\subsection{La omisión de la acción de reelaboración ante información existente que solo requiere ser recopilada}

Con posterioridad a la elaboración de este criterio interpretativo, se han dictado algunas sentencias en procesos entablados contra resoluciones del CTBG, cuya argumentación jurídica principal giraba en torno a la inadmisión de solicitudes de acceso por este motivo. Resultan de especial interés los litigios con la CRTVE en relación a sus costes, y por ello, se analizan las sentencias relativas a los casos que denominaremos "Coste de los canales de televisión» ${ }^{49}$, que fallan en contra del criterio del CTBG y a favor de la CRTVE; «Coste del Festival de Eurovisión 2015» ${ }^{50}$, que lo hacen a favor del Consejo; y las sentencias que, -en di-

25 de junio, del Patrimonio Histórico Español señala que: «se entiende por documento, a los efectos de la presente Ley, toda expresión en lenguaje natural o convencional y cualquier otra expresión gráfica, sonora o en imagen, recogidas en cualquier tipo de soporte material, incluso los soportes informáticos». Por si no fuera suficiente, la LTBG añade, junto a la información documentada, la accesibilidad de los «contenidos» en general (art. 13).

47 Esta reflexión se realizaba en relación a una perturbadora disposición en parecido sentido contenida, hasta 2013, en el art. 37.3 de la LRJ-PAC: «el derecho de acceso será ejercido por los particulares de forma que no se vea afectada la eficacia del funcionamiento de los servicios públicos».

48 En su estudio conjunto sobre la doctrina del CTBG y de los organismos de garantía del derecho de acceso de las Comunidades Autónomas, BARRERO RODRÍGUEZ (2017: 30 y 31) considera el contenido de la Resolución 36/2015, de 11 de febrero de 2016, de la Comisión de Garantía del Derecho de Acceso a la Información Pública de Cataluña como un ejemplo de delimitación de los criterios aplicables ante esta causa de inadmisión, bajo la redacción de la Ley de transparencia catalana, que se refiere a ella como «una tarea compleja de elaboración de reelaboración». Así, en dicha resolución se califican como «indicios» para la existencia de la mencionada consideración los siguientes supuestos, traducidos por la propia autora a partir de la resolución original: «a) Que se deba extraer la información solicitada de documentos que tienen un contenido más amplio, especialmente si esta tarea se debe hacer manualmente y en relación con varios documentos archivados en diferentes expedientes, y más aún si la información que se debe extraer no es simple y directa y requiere una cierta actividad de análisis o de interpretación; b) Que sea necesario obtener la información solicitada de bases de datos o de archivos digitales, y que sea necesario a estos efectos utilizar programas informáticos más o menos especializados o sofisticados; c) Que sea necesario obtener la información solicitada combinando bases de datos o archivos electrónicos y archivos en papel, requiriendo además una tarea de análisis o de interpretación, d) Que la información solicitada corresponda a un lapso temporal muy amplio, de modo que haya que buscarla entre varios expedientes cronológicamente alejados e incluso entre varios contenedores o ámbitos físicos de archivo de documentos; e) Que sea necesario obtener la información solicitada de un número muy elevado de documentos y de expedientes diferentes, especialmente si se encuentran dispersos, bien sea por razones cronológicas o de cualquier otra índole; y f) Otros indicadores en base a los cuales se pueda argumentar razonadamente que la tarea de búsqueda y obtención de la información solicitada no es sencilla». Como también destaca la autora, cabe mencionar que en la resolución se apunta a dos posibilidades para entender que concurre la causa de inadmisión: ante uno solo de los indicios, si este muestra una elevada intensidad; $\mathrm{o}$ ante varios de ellos conjuntamente, aun mostrando una intensidad más reducida.

49 SJCCA núm. 9, de 25 de abril de 2016, núm. 60/2016 y SAN, de 24 de enero de 2017, Sec. 7, núm. Res. 29/2017.

50 SJCCA núm. 6, de 18 de mayo de 2016, núm. 60/2016; SAN, de 7 de noviembre de 2016, núm. Res. 432/2016, Sec. 7; y STS, de 16 de octubre de 2017, núm. 1547/2017, Sec. 3. ${ }^{\text {. }}$. 
REALA. Nueva Época - N. ${ }^{\circ}$ 11, Abril-Septiembre 2019 - ISSN: 1989-8975 - DOI: 10.24965/reala.v0i11.10581 - [Págs. 56-74]

Inadmisión y necesidad de reelaboración ante el derecho de acceso a la información pública

Manuel Fernández Salmerón / Javier Sierra Rodríguez

recciones opuestas-, se pronunciaron sobre el «Coste de Gala Fin de Año 2015» ${ }^{51}$ y el «Coste del Especial Nochebuena y Campanadas 2016» ${ }^{52}$.

Como decimos, las sentencias se han dictado en sentidos dispares respecto a la posición del CTBG, pero llama especialmente la atención que, ante supuestos que guardan cierta identidad, como la obtención del coste de participación en Eurovisión y los de producción de programas, los pronunciamientos judiciales hayan ido en direcciones distintas. De ahí la importancia de contar con una sentencia dictada en casación por el Tribunal Supremo en torno al caso «Coste del Festival de Eurovisión 2015».

\section{a) Caso canales de televisión: producción de información inexistente}

Entrando en el análisis y en los criterios de interpretación de los órganos jurisdiccionales, en el caso «Coste de los canales de televisión» las diferencias entre el CTBG y la CRTVE se centraban, entre otros argumentos, en la posible aplicación del supuesto de inadmisión por reelaboración. El CTBG defendía que la información se encontraba en poder de la Corporación y que ésta contaba con los medios personales y materiales necesarios para obtenerla, por lo que la solicitud no debería haberse considerado dentro del supuesto de inadmisión por necesidad de reelaboración.

Sin embargo, y sin negar los argumentos del CTBG, el Juez consideró especialmente el hecho de que la contabilidad de la CRTVE se lleva a cabo de forma conjunta para todos los canales, por lo que su individualización conllevaría elaborar una nueva contabilidad separada por canales de cara a satisfacer el derecho de acceso; es decir, conduciría a una verdadera acción de reelaboración. Además, el juzgador expuso, como añadido, la existencia de una serie de gastos generales comunes, así como la producción de programas que se difunden en varias de sus emisiones, cuya individualización por canales supondría un considerable ejercicio de imputación de los gastos no exento de dificultades ${ }^{53}$.

Por ese motivo, concluyen los órganos judiciales que el derecho de acceso no comprende el deber de la Administración de producir o generar información que no tenía. Pero la Audiencia Nacional ${ }^{54}$ va incluso más allá, al considerar que el derecho de acceso «no puede ser confundido con el derecho a la confección de un informe por un órgano público a instancia de un particular» ${ }^{55}$.

De este modo, el Juez aclara, más que cualquier contenido del criterio interpretativo $\mathrm{Cl} 7 / 2015$, cuál debe ser el extremo a considerar en el concepto de reelaboración, muy en línea con lo afirmado por BLANES CLIMENT (2015), quien apostaba porque dicho concepto «acción de reelaboración» quede «circunscrito a elaborar estudios, investigaciones, comparativas o análisis ex professo» ${ }^{56}$.

Al margen de lo examinado, la sentencia resta valor a uno de los elementos fijados en los criterios interpretativos del CTBG para apreciar que existe reelaboración, y que consiste en que sea necesario hacer uso de diversas fuentes de información ${ }^{57}$. Al respecto la Audiencia Nacional menciona que, para su apre-

51 SJCCA núm. 9, de 21 de abril de 2017, núm. 60/2017 y SAN, de 11 de septiembre de 2017, Rec. 51/2017, Sec. 7. ${ }^{\text {. }}$

52 SJJCA núm. 5, de 28 de febrero de 2018, núm. 28/2018, corregida por SAN, de 2 de julio de 2018, Rec. 47/2018, Sec. 7. ${ }^{\text {a }}$

53 Así expresa el Juez «La demandante sostiene que para determinar el coste de cada canal no bastaría con buscar entre las cifras contenidas en la contabilidad de la CRTVE, ... sino que habría que realizar una tarea no fácil para obtener unas cifras que a día de hoy no se tienen...», concluyendo que «la información requerida precisaría realizar nuevas operaciones de análisis, agregación e interpretación, por lo que la interpretación que hace el Consejo, resulta excesivamente restrictiva y contraria al espíritu de la norma» (SJCCA núm. 9, de 25 de abril de 2016, núm. 60/2016, FJ 4. ${ }^{\circ}$ ).

54 SAN, de 24 de enero de 2017, Sec. 7. ${ }^{a}$, núm. Res. 29/2017, FJ 4..

55 Recordamos, nuevamente, que desde hace años el ordenamiento jurídico italiano ha venido siguiendo una orientación similar. La legislación y la jurisprudencia del Consejo de Estado italianos han concluido que no es posible pretender el acceso a informaciones que no cuenten ya con forma documental en el momento en que se ejercita el derecho, o que impliquen una recopilación, mediante una específica tarea de investigación y elaboración (ROMANO, 2016: 946-947). En su configuración global, es incluso más restrictiva que la nuestra, pues ha reducido durante años el derecho de acceso a la información, no solo documentada -algo que, aunque con un alcance bastante más amplio, ha compartido con el sistema español-, sino vinculada, además, a procedimientos decisorios de las Administraciones Públicas. Por el contrario, el Derecho italiano conoce, al margen del derecho de acceso, manifestaciones del «derecho a conocer» (right to know) o simple «derecho a la transparencia del aparato público», desvinculadas de estas y otras rígidas exigencias, como la legitimación, incorporación de la información a procedimientos, etc., a través de deberes específicos de publicidad activa y del llamado accesso civico. (CANAPARO, 2014).

56 Llama la atención el cruce de posiciones e interpretaciones que se produce en este caso. Es el CTBG quien ha mostrado una interpretación más laxa sobre esta causa de inadmisión, es decir, que su criterio interpretativo admitía más supuestos por los que se podría considerar que existe reelaboración, y bajo dichos criterios defendía una posición favorable al acceso a la información. Sin embargo, las sentencias sobre este caso fallan en contra de la posición del CTBG, y asumen que se produce la causa de inadmisión, incluso partiendo de un criterio más restrictivo de esta causa de inadmisión.

57 El CTBG expresa que puede apreciarse la existencia de acción de reelaboración cuando la información deba: «a) Elaborarse expresamente para dar una respuesta, haciendo uso de diversas fuentes de información, o b) Cuando dicho organismo o entidad ca- 
REALA. Nueva Época - N. ${ }^{\circ} 11$, Abril-Septiembre 2019 - ISSN: 1989-8975 - DOI: 10.24965/reala.v0i11.10581 - [Págs. 56-74]

Inadmisión y necesidad de reelaboración ante el derecho de acceso a la información pública

Manuel Fernández Salmerón / Javier Sierra Rodríguez

ciación, «es indiferente que dicha información obre en poder de la Administración o ente público encargada de dispensarla», es decir, no se observa que esta situación pueda por sí sola hacer que una información se considere que requiera reelaboración ${ }^{58}$.

\section{b) Caso Eurovisión 2015: simplicidad del tratamiento necesario}

El siguiente caso que se analiza, tiene su origen en una solicitud de acceso a la información relativa a los gastos en que había incurrido la CRTVE para participar en el Festival de Eurovisión de 2015. El punto de partida era algo distinto al anterior, porque la CRTVE no dictó una resolución de inadmisión de la solicitud, sino que simplemente no respondió. El órgano judicial argumentó que, al no resolverse en plazo la solicitud y entenderse la misma desestimada, no debería poder alegarse -incluso en el procedimiento de reclamación ante el CTBG- causa alguna de inadmisión, dado que la Corporación no la hizo expresa en su momento mediante resolución expresa ${ }^{59}$.

Pese a ello, el juzgador entra a examinar si concurrían o no razones para la inadmisión, destacando la falta de motivación por parte de la recurrente, CRTVE, de que lo solicitado implicara un ejercicio complejo que condujese a una reelaboración. Junto a ello, el Juez descarta que la información solicitada comportase una acción de reelaboración, porque no va «más allá de constatar las distintas partidas en que se contengan los datos de los gastos efectuados» ${ }^{60}$, para poder extraer una cuantía global. De este modo, da la razón al CTBG y entiende procedente el acceso, considerando como elemento clave la falta de justificación de la causa de inadmisión una vez en la vía judicial. Además, a criterio del órgano jurisdiccional, una de las razones favorables al acceso, consistía en que el tratamiento necesario para obtener la información era simple, por lo que no se podía considerar una operación de reelaboración. La sentencia fue confirmada en grado de apelación y, de nuevo, en Casación ante el Tribunal Supremo, que volvió a destacar como elemento principal la falta de justificación de la inadmisión, por parte de la CRTVE:

«Por ello, la causa de inadmisión de las solicitudes de información que se contempla en el artículo 18.1c) de la Ley 19/2013, de 9 de diciembre, no opera cuando quien invoca tal causa de inadmisión no justifique de manera clara y suficiente que resulte necesario ese tratamiento previo o reelaboración de la información ${ }^{61}$.

\section{c) Caso: Gala Fin de Año 2015: producción de información inexistente}

También se analiza el caso correspondiente a los «Gastos de la Gala Fin de Año 2015» ${ }^{62}$. En concreto, la Corporación RTVE recurrió contra una resolución del CTBG en la que se estimaba la procedencia del acceso a información económica sobre los gastos de la Gala Especial Fin de Año 2015. Una vez examinada, la razón que fundamenta el sentido de la sentencia en favor de la CRTVE -denegando el acceso-, consiste en que la información contable no está individualizada por programas y que proceder a dicha individualización supondría una clara operación de reelaboración de la información, lo que constituye precisamente una de las causas de inadmisión legalmente previstas (art. 18.1 c LTBG). Entiende el Juez que la interpretación del CTBG, -el cual no observa la concurrencia de motivo alguno de inadmisión-, «resulta excesivamente restrictiva y contraria al espíritu de la norma», en el sentido de minusvalorar el trabajo de reelaboración que conlleva otorgar el acceso. Asimismo, en interpretación del artículo 13 LTBG -que ofrece el concepto legal de información pública-, la sentencia añade que el derecho de acceso invocado se proyecta respecto «a la información que existe y que está ya disponible, lo que es distinto de reconocer el derecho a que la Administración produzca, aunque sea con medios propios, información que antes no tenía» (FJ 6. ${ }^{\circ}$ ).

El argumento de la sentencia sobre la Gala de Fin de Año 2015 parece ir en la línea de evitar que las solicitudes de acceso permitan que se obligue a la Administración a elaborar informes o estudios «a la car-

\footnotetext{
rezca de los medios técnicos que sean necesarios para extraer y explotar la información concreta que se solicita, resultando imposible proporcionar la información solicitada».

58 SAN, de 24 de enero de 2017, Sec. 7. a núm. Res. 29/2017, FJ 4.․

59 Sobre este concreto problema del silencio administrativo y la inadmisión de solicitudes de acceso, remitimos al análisis que hemos desarrollado supra, 2.2 .

60 SJCCA núm. 6, de 18 de mayo de 2016, núm. 60/2016, FJ 3..

61 STS, de 16 de octubre de 2017, núm. 1547/2017, Sec. 3. a , FJ 6. ${ }^{\circ}$

62 SJCCA núm. 9, de 21 de abril de 2017, núm. 60/2017.
} 
ta», pero su aplicación al caso concreto de los gastos de dicha Gala parece estar forzada, ya que, a priori, no se observa que el reconocimiento del acceso conllevase una complejidad mayor de cara a la entrega de la información que en el caso "Gastos de Eurovisión» ${ }^{63}$.

La aplicación de este razonamiento en relación al caso Gastos de la Gala Fin de Año 2015 parece contraria a la postura que se ha venido manteniendo por el CTBG, que admite la necesidad de un mínimo de elaboración de la información -para diferenciarlo del «derecho al dato» o «al documento»-, además de suponer una interpretación restrictiva del concepto mismo de información pública. En este caso, existen elementos que el CTBG ha considerado fundamentales en sus criterios interpretativos para dilucidar si se está o no ante el supuesto de inadmisión por reelaboración, como es el hecho de que toda la información necesaria está en poder de la CRTVE y que se disponga de los medios necesarios para suministrarla ${ }^{64}$.

Sorprende que en esta última sentencia, confirmada en apelación, pero en fecha anterior a la STS sobre el coste de Festival de Eurovisión $2015^{65}$, el juzgador interprete de manera extensa las causas de inadmisión -o, de otro modo, sea restrictivo en su interpretación jurídica, pero laxo en la apreciación del esfuerzo necesario para entregar la información-, al entender que sí suponía una amplia carga y estimar que concurre la causa de inadmisión. Esta postura tiene como contrapartida, según venimos señalando a lo largo de este trabajo, una correlativa reducción del alcance del derecho, justamente todo lo contrario de lo que postula al espíritu de la norma y de lo expresado en su Preámbulo, que se ha erigido en una de las pautas interpretativas principales para otros pronunciamientos judiciales, como sucede en el caso de la sentencia de casación a la que se ha hecho referencia.

Adicionalmente, se observa que los casos "Costes de Eurovisión» y "Costes de la Gala Fin de Año 2015» guardan cierta identidad en lo que respecta al trabajo de elaboración que puedan conllevar, por lo que Ilama la atención lo contradictorio de las sentencias ${ }^{66}$, algo muy distinto a la amplitud del trabajo de reelaboración que podría originar la pretensión del solicitante en el caso de los «Coste de los canales de televisión».

\section{d) Caso: Especial Nochebuena y Campanadas 2016: recopilación de información existente}

Tras la STS sobre el coste de Festival de Eurovisión 2015 parece que todo este vaivén interpretativo que se ha analizado va encauzándose, aunque no sin dificultades, porque en otro de los casos, "Coste especial Nochebuena y Campanadas 2016», la sentencia de primera instancia aplicaba un criterio restrictivo, que posteriormente fue corregido en apelación, compartiendo ya plenamente el planteamiento del Tribunal Supremo, al enfatizar que «no se aprecia que para facilitar tales datos haya que hacer un trabajo específico, es simplemente recopilarlos». De este modo, se reiteran los argumentos que alejan a una solicitud de la causa de inadmisión y, adicionalmente, se destaca el hecho de que la solicitud está alineada con la finalidad de la Ley, porque «lo que se pretende es saber de qué manera y cómo la CRTVE ha gastado el dinero que recibe» ${ }^{67}$.

Es necesario reiterar, que un requisito que se considera clave para la apreciación de la causa de inadmisión, consiste en que la información ya exista -aspecto distinto es el relativo a dónde situar la línea divisoria entre el mínimo tratamiento que se precisa para disponer de ella y la consideración de reelaboración-. Por ello, se entiende que la postura que debe ir prevaleciendo en estos casos -ante información existente-, es que solo sea necesaria su agregación para poder obtener los costes sin necesidad de que exista labor de reelaboración.

En otros pronunciamientos, que vienen a utilizar criterios jurisprudenciales en la misma línea que los ofrecidos por la STS del caso sobre los costes de Eurovisión, se rechaza la aplicación de esta causa de

63 No obstante, es cierto que la sentencia de apelación considera y razona de manera más extensa la concurrencia de circunstancias adicionales en este caso, como el hecho de que la solicitud no se limitaba a los gastos de la gala en directo y la parte emitida en diferido, sino que también incorporaba aspectos como las empresas intervinientes, lo que podía afectar a intereses de terceros, y los tipos de contratos celebrados con los presentadores, que no se consideraban elementos que entrasen dentro de las finalidades que busca la LTBG, entre otros. Véanse los FFJJ $4 .^{\circ}$ y $8 .^{\circ}$ de la SAN, de 11 de septiembre de 2017, Rec. 51/2017, Sec. 7. . $^{2}$

64 No debe olvidarse que, en la mecánica de la LTBG, la información accesible ha de estar, en efecto, documentada, pero el derecho no se ejerce sobre el documento o soporte en sí (como ha venido sucediendo en Italia), sino sobre la información misma, lo que, de ordinario, puede conllevar el despliegue, por parte del sujeto público requerido, de, al menos, ciertas operaciones de adaptación.

65 SAN, de 11 de septiembre de 2017, Rec. 51/2017, Sec. 7. ${ }^{\mathrm{a}}$.

66 No obstante, es asimismo cierto que en el caso «Costes de Eurovisión», en el que se rechazó la causa de inadmisión, pesaba el argumento de que la CRTVE no resolvió tempestivamente la solicitud de acceso a la información y de que, por tanto, se entiende que no podía pronunciarse una inadmisión, dado que esta hubiese requerido una resolución expresa, según ya vimos.

67 SAN, de 2 de julio de 2018, Rec. 47/2018, Sec. 7. ${ }^{\text {, }}$ FJ 4. ${ }^{\circ}$. 
inadmisión cuando, por ejemplo, se trata de recopilar información existente en los órganos de contratación -pese a su amplio número-, porque dicha operación de acopio, como tal, no supone reelaboración y «se trata de información que ya existe, es decir que no precisa ser reelaborada para proporcionar el acceso sin perjuicio de que pueda no existir un repositorio común a todos..., a lo sumo, lo requerido supondría una labor de recopilación de datos con el alcance de agregar, tratar o adicionar los mismos pero sin que requiera una labor de elaboración o creación ad hoc a modo de informe» ${ }^{68}$. Además, en la misma sentencia se insiste en que el hecho de que la información esté dispersa en diversos órganos identificados es relevante de cara al procedimiento para conseguir la información (art. 19 LTBG), pero en ningún caso para hacer valer la pretensión de que proceda la inadmisión.

\section{A MODO DE CONCLUSIÓN}

Las causas de inadmisión que se contemplan en la LTBG son susceptibles de diferentes interpretaciones, al haber recurrido el legislador en su configuración a conceptos indeterminados o que, en todo caso, requieren de la formulación de un juicio de valor, en atención a las circunstancias de cada caso concreto. Tales supuestos se encuentran, en consecuencia, escasamente perfilados en la LTBG y, por ello, se considera imprescindible recurrir a herramientas, como los criterios interpretativos, que han guiado en muchos casos la interpretación de jueces y tribunales. No obstante, resulta poco comprensible que, transcurridos más de cinco años desde la publicación de la Ley, no se hayan evacuado dichos criterios sobre la totalidad de las causas de inadmisión.

Las sentencias dictadas sobre la materia muestran una sensible tendencia a la adopción de una interpretación expansiva del derecho de acceso, lo que implica correlativamente, una óptica restrictiva respecto a la aplicación de las causas de inadmisión, en la línea del cambio de modelo que se produce con el tránsito desde la redacción inicial de la Ley 30/1992, a la resultante tras la LTBG y la nueva regulación sobre el régimen jurídico de las Administraciones Públicas y el procedimiento administrativo común de 2015, que han conducido a un nuevo paradigma de apertura a la información que podríamos denominar de «accesibilidad por defecto».

Debido a esta visión expansiva del derecho en examen, podría resultar controvertido que algunas Comunidades Autónomas hayan establecido reglas de aplicación de las causas de inadmisión que, en algún caso, arrojan dudas sobre un posible alejamiento respecto de lo establecido en la disciplina básica, en tanto que puedan ampliar indebidamente su espectro regulador. No obstante y por lo general, las normas autonómicas secundan de modo conveniente la regulación estatal básica, incurriendo incluso en la habitual corruptela de reiterar los supuestos de inadmisión de la LTBG y, por ello, de consagrar preceptos muy similares entre sí, con la consiguiente sobrecarga e ineficacia en el funcionamiento del sistema normativo.

Del análisis jurisprudencial realizado se deriva que, en muchos casos, los sujetos públicos obligados por la actio ad exibendum administrativa, muy al contrario que los tribunales, han aplicado un criterio expansivo en la interpretación de las causas de inadmisión. Así, han sido esgrimidas de manera recurrente argumentaciones de este alcance para no dar curso a las solicitudes, siendo habitual que en procedimientos judiciales se combine la alegación simultánea de causas de inadmisión y de límites sustantivos al ejercicio del derecho, práctica que supone un mero recurso defensivo ante una firme voluntad de zafarse de la solicitud de información. También se observa la importancia que se otorga a la motivación de la causa de inadmisión, ya que en algunos casos, la misma ha sido rechazada por no haber sido justificada suficientemente su concurrencia.

La alegación de causas de inadmisión ha llegado a producirse incluso de modo extemporáneo, en el marco de procesos judiciales suscitados a partir de procedimientos concluidos mediante silencio administrativo. Al respecto, los tribunales han entrado a valorar tal alegación extemporánea, lo que parece acertado ante causas de inadmisión que, por su naturaleza, no sean apreciables con claridad al inicio del procedimiento administrativo (reelaboración, información en curso de elaboración y de carácter auxiliar o de apoyo), mientras que sobre otros motivos (solicitudes repetitivas y abusivas y dirigidas a un órgano que no posea la

68 SJCCA núm. 1, de 14 de febrero de 2018, núm. 15/2018, FJ 3.․ Otras sentencias que manejan similares argumentaciones y que se proyectan sobre una serie de casos asimilables respecto a solicitudes de información de costes de campañas de comunicación, enfatizan la importancia de la preexistencia de la información solicitada y el hecho de que su recopilación no puede ser considerada como una acción de reelaboración. Véase SJCCA núm. 4, de 26 de febrero de 2018, núm. 26/2018; SJCCA núm. 2, de 22 de noviembre de 2018, núm. 139/2017; SJCCA núm. 3, de 16 de mayo de 2018, núm. 63/2018, entre otras. 
REALA. Nueva Época - N. ${ }^{\circ}$ 11, Abril-Septiembre 2019 - ISSN: 1989-8975 - DOI: 10.24965/reala.v0i11.10581 - [Págs. 56-74]

Inadmisión y necesidad de reelaboración ante el derecho de acceso a la información pública

Manuel Fernández Salmerón / Javier Sierra Rodríguez

información y se desconozca el competente) no nos parece correcta la admisión de su invocación procesal ex novo, con fundamento en la razón rigurosamente inversa. Al margen de ello, la jurisprudencia también ha reconocido la capacidad del CTBG para apreciar la concurrencia de una causa de inadmisión en el seno de un procedimiento de recurso verificado ante esta última instancia administrativa, aun cuando la solitud inicial no se hubiera denegado por este motivo.

En cualquier caso, resulta llamativo que no exista un mayor reproche judicial a esta práctica, que elude la obligación de motivar la existencia de la causa de inadmisión y que, además, puede ser constitutiva de infracción grave en aplicación del régimen disciplinario previsto en la LTBG.

La necesidad de una acción de reelaboración, ha sido una de las causas más habitualmente invocadas en sede judicial por parte de los sujetos pasivos del derecho de acceso. Tal y como se ha analizado, los jueces y tribunales han adoptado posturas distintas, e incluso contradictorias, respecto de los criterios sentados por el CTBG, matizando aspectos contemplados en sus líneas interpretativas, como la necesidad de acudir a diversas fuentes para el acceso a la información, circunstancia que por sí sola no puede fundamentar un pronunciamiento de inadmisión, o asumiendo que no concurre tal acción de reelaboración, cuando la debida atención de la solicitud de acceso comporte únicamente un tratamiento informatizado de uso corriente.

La doctrina judicial ha ido en la línea de valorar la complejidad de la tarea que supone el acceso a la información, admitiendo que existe un mínimo de carga de trabajo derivado de las labores necesarias para facilitar el acceso, como es la agregación de información procedente de diversas fuentes o de información que ya existe, alejándose de este modo de cualquier reconocimiento de un derecho a obtener información o informes a la carta. La pre-existencia de la información es un factor clave, pero también lo es la apreciación del tratamiento mínimo que se precisa para facilitarla, cuyos contornos no han sido delimitados con claridad, ni por la jurisprudencia analizada, a veces contradictoria, ni por los criterios elaborados por el CTBG, por lo que es previsible que sigan produciéndose litigios frecuentes en torno a esta causa de inadmisión.

No obstante, parece que la interpretación de jueces y tribunales va encauzándose tras la intervención del Tribunal Supremo, aunque la casuística es muy diversa y será necesario contar con más aclaraciones judiciales, pues en la actualidad cualquier solución interpretativa se torna compleja. En esta línea, ha de subrayarse que el aprendizaje adquirido en la interpretación de las causas de inadmisión, debiera plasmarse adecuadamente en el desarrollo reglamentario de la Ley, actualmente en curso, y derivar asimismo en la modificación y el perfeccionamiento de los criterios interpretativos confeccionados por el CTBG.

\section{REFERENCIAS BIBLIOGRÁFICAS}

BARRERO RODRÍGUEZ, C. (2017): "Las causas de inadmisión de las solicitudes de acceso a la información; en particular, la doctrina de las autoridades independientes", en Revista General de Derecho Administrativo, núm. 46, págs. 1-46.

BLANES CLIMENT, M. A. (2015): “¿Qué es «información auxiliar o de apoyo» y «reelaborar»?” [Entrada de blog]. Transparencia y Gobierno Abierto. Recuperado de https://miguelangelblanes.com/2015/11/27/que-es-informacionauxiliar-o-de-apoyo-y-reelaborar/ (27 de noviembre de 2015) (acceso 01-08-2018).

CANAPARO, P. (2014): "La via italiana alla trasparenza pubblica: il diritto di informazione indifferenziato e il ruolo proattivo delle pubbliche amministrazioni", en Federalismi.it. Rivista di diritto pubblico italiano, comunitario e comparato, núm. 4, págs. 37-49.

CARLONI, E. (2014): L'amministrazione aperta. Rimini: Maggioli.

CIERCO SEIRA, C. (2009): La inadmisión en el procedimiento administrativo. Estudio de su configuración a la luz del proceso judicial. Madrid: lustel.

CLAVERO ARÉVALO, M. F. (1963): "El carácter revisor de la jurisdicción contencioso-administrativa y las sentencias anulatorias de actos en los que la Administración no entró en el fondo del asunto", en Revista de Administración Pública, núm. 42, págs. 217-228.

COTINO HUESO, L. (2017): "El reconocimiento y contenido internacional del acceso a la información pública como derecho fundamental”, en Teoría y Realidad Constitucional, núm. 40, págs. 279-316. DOI: https://doi.org/10.5944/ trc.40.2017.20910.

COTINO HUESO, L. (2014): "El derecho fundamental de acceso a la información, la transparencia de los poderes públicos y el gobierno abierto. Retos y oportunidades”, en VALERO TORRIJOS, J. y FERNÁNDEZ SALMERÓN, M. (coords.): Régimen jurídico de la transparencia en el sector público, págs. 37-71. Cizur Menor: Aranzadi.

DE LA NUEZ SÁNCHEZ-CASADO, E. (2017): "La transparencia pendiente: consideraciones sobre la consulta pública del borrador de Reglamento de la Ley de Transparencia”, en Revista Española de la Transparencia, núm. 4, págs. 6-8. 
FERNÁNDEZ RAMOS, S. (2003): Los concejales y el acceso a la información (el derecho de los concejales de acceso a la documentación local), 2. ${ }^{a}$ ed. Granada: Comares.

FERNÁNDEZ RAMOS, S. (2013): "El acceso a la información en el proyecto de ley de transparencia, acceso a la información pública y buen gobierno", en Monografías de la Revista Aragonesa de Administración Pública, vol. XIV, págs. 233-298.

FERNÁNDEZ RAMOS, S. (2017a): "El silencio administrativo en el ejercicio del derecho de acceso a la información pública: entre el abuso de la administración y el voluntarismo del legislador", en Revista Española de Transparencia, núm. 4, págs. 46-65.

FERNÁNDEZ RAMOS, S. (2017b): “El derecho fundamental de acceso a la información pública”, en Cuadernos Manuel Giménez Abad, núm. 13, págs. 188-206.

FERNÁNDEZ RAMOS, S. y PÉREZ MONGUIÓ, J. M. (2017): El derecho de acceso a la información pública en España. Pamplona: Aranzadi.

FERNÁNDEZ SALMERÓN, M. (2014): "Procedimiento administrativo e información del sector público", en VALERO TORRIJOS, J. y FERNÁNDEZ SALMERÓN, M. (coords.): Régimen jurídico de la transparencia en el sector público, págs. 281-321. Cizur Menor: Aranzadi.

GUICHOT REINA, E. (2014): "Capítulo II. Transparencia. Aspectos generales”, en GUICHOT REINA, E. (coord.): Transparencia, acceso a la información pública y buen gobierno, págs. 35-62. Madrid: Tecnos.

MORETÓN TOQUERO, A. (2014): "Los límites del derecho de acceso a la información pública", en Revista Jurídica de Castilla y León, núm. 33, págs. 1-24.

ORTEGA ÁLVAREZ, L. I. (2003): "El derecho de acceso de los miembros de las corporaciones locales a la documentación existente en la corporación", en Cuadernos de Derecho Local, núm. 2, págs. 67-77.

SÁNCHEZ DE DIEGO FERNÁNDEZ DE LA RIVA, M. (2016). "El principio de transparencia y el derecho de acceso a la información pública”, en CASCAJO CASTRO, J. L. y MARTíN DE LA VEGA, A.: Participación, Representación y Democracia. XII Congreso de la Asociación de Constitucionalistas de España, págs. $297-318$. Valencia: Tirant Lo Blanch.

RAMS RAMOS, L. (2013): "La transformación del derecho de acceso en España: de derecho de configuración legal a derecho fundamental", en Revista Española de Derecho Administrativo, núm. 160, págs. 155-188.

RAMS RAMOS, L. (2016): "El procedimiento de ejercicio del derecho de acceso a la información pública”, en Revista General de Derecho Administrativo, núm. 41, págs. 1-46.

ROMANO, A. (2016): "L'accesso ai documenti amministrativi”, en ROMANO, A. (a cura di): L'azione amministrativa, págs. 910-969. Torino: Giappichelli Editore.

SENDÍN GARCÍA, M. A. (2014): "Transparencia y acceso a la información pública”, en RODRÍGUEZ ARANA MUÑOZ, J. y SENDÍN GARCÍA, M. A.: Transparencia, acceso a la información y buen gobierno, págs. 150-160. Granada: Comares.

VALERO TORRIJOS, J. y FERNÁNDEZ SALMERÓN, M. (coords.) (2014): Régimen jurídico de la transparencia en el sector público. Cizur Menor: Aranzadi. 